\title{
The Interpretation and Screening of Learning Difficulties in Mathematics: Regard at the Contribution of the Anthropo-Didactic Approach
}

\author{
Thomas Rajotte ${ }^{1,}$, , Marie-Paule Germain ${ }^{1}$, Sylvain Beaupre ${ }^{2}$, Raphaelle Dufour ${ }^{1}$ \\ ${ }^{1}$ Department of Education, University of Quebec at Rimouski, Quebec, Canada \\ ${ }^{2}$ Department of Education, University of Quebec in Abitibi-Temiscamingue, Quebec, Canada
}

Email address:

Thomas_rajotte@uqar.ca(Thomas R.),mpgermain@hotmail.com (Marie-Paule G.), beaupre.syvlain@uqat.ca (Sylvain B.),

Raphaelle.dufour@uqar.ca (Raphaelle D.)

${ }^{*}$ Corresponding author

\section{To cite this article:}

Thomas Rajotte, Marie-Paule Germain, Sylvain Beaupre, Raphaelle Dufour. The Interpretation and Screening of Learning Difficulties in Mathematics: Regard at the Contribution of the Anthropo-Didactic Approach. International Journal of Elementary Education.

Vol. 10, No. 3, 2021, pp. 42-55. doi: 10.11648/j.jjeedu.20211003.11

Received: July 27, 2021; Accepted: August 6, 2021; Published: August 12, 2021

\begin{abstract}
The aim of this study is to increase knowledge about learning difficulties in mathematics by exploring how different explanatory perspectives on learning difficulties influence the discourse of educational specialists when they take a position on the foundations of learning difficulties in the field of mathematics. A literature review of the learning difficulties in mathematics researches of the last thirty years shows the emergence of two major interpretative perspectives. In the first one, the difficulties are interpreted in terms of the learners' cognitive characteristics, while the second perspective study learning difficulties as the result of interactions between the student and the school system. Many debates during the last few decades between the proponents of the first perspective and those of the second perspective brought out a third perspective: the anthropo-didactic approach. This research aims to test the relevance of this third perspective by analyzing the discourse of different education professionals. Since this third interpretive perspective of learning disabilities has recently appeared in the scientific literature, to our knowledge, no research to validate this perspective has been done in Canada. Through semi-structured interviews, 14 educational specialists shared their experience and their vision regarding the interpretation of learning difficulties in mathematics. Moreover, they discussed the different methods for screening those difficulties. The results obtained through analysis of their discourse highlight different themes connected to three explanatory perspectives (cognitivist, didactic and social science). In addition, the results reveal the complementary contribution of the anthropo-didactic approach (related to the social science perspective) which, owing to its recent emergence in the Quebec scholarly research, is rarely considered by researchers and professionals working in the field of education.
\end{abstract}

Keywords: Mathematics, Elementary School, Learning Difficulties, Screening, Anthropo-Didactic Approach, Explanatory Perspectives

\section{Introduction}

This research is enrolled in the line of works on learning difficulties in mathematics [1-4]. Mathematical learning difficulties have been studied by three perspectives: the cognitive sciences, the didactic and the anthropo-didactic approach [1, 3, 5-9]. This approach considers the necessity to adopt an anthropologic view which allows treating cultural variables (social values and institutional influences) in the explanation of students' mathematical difficulties [10]. Through this study, we wish to contribute, by adopting an anthropo-didactic approach, to document how the different explanatory perspectives influence the discourse of educational professionals when they take position about interpretation's modalities of learning difficulties in mathematics as well as their screening modalities. In addition, through this research, we want to verify if the consideration of the professional generates a complementary contribution to 
both traditional perspectives about the interpretation of the nature of these learning difficulties as carried out by professionals from the education sector.

\section{Problematic}

At the end of the $90 \mathrm{~s}$, in the line of works of the Commission des États généraux sur l'éducation, the Ministry of Education of Quebec has set itself a major challenge, which was to take "le virage du succès" to use the exact expression [11-14]. Essentially, this new orientation aimed the success of the greatest number thanks to different concerted actions by different actors from the education sector $[13,15]$. Despite the efforts made by the actors of the school system since this new position of the ministry, carry on interventions with SHSMLD is still a major issue in 2021.

Indeed, the school dropout rate of this group of students $(46,8 \%)$ is nearly three times higher than the rate of all Quebec students $(16,2 \%)$ [16], while the SHSMLD represent almost 1 on $5(20,5 \%)$ of the student population according to Homsy and Savard [17]. This situation is partly explained by the fact that the integration model of SHSMLD within regular classes would not meet their learning needs [18]. Thereupon, since the most recent reform of the Quebec education system, teachers need to adapt their pedagogic interventions to the SHSMLD characteristics and needs $[13,14,19,20]$ and the field of mathematics is not exempted [21].

\subsection{Learning Difficulties: Two Traditional Perspectives and Their Limits}

A look at the scientific works of the last 30 years allows revealing that two perspectives can explain mathematics learning difficulties of primary students [4, 21]. The cognitivist theory, which relates to the areas of developmental psychology, the neuropsychology and the cognitive sciences $[22,23]$, is essentially based on the identification and the description of the student dysfunction. The didactic perspective, for its part, is interested in the operation of the didactic system and phenomenon that characterize the relationships between the student's production, the effective teaching situation and the specificity of knowledge [24].

Giroux [3] believes it would be unlikely to differentiate the pedagogic intervention depending on the nature of the difficulties because teachers have little theoretical support and didactic resources. Also, recent cognitive sciences' works obtained little empirical results [3, 7] and the writing of mathematics didactic can difficultly be generalized to a large population of students [3]. Learning difficulties requires, according to Giroux [3], analytical tools from the social sciences.

Consequently, sociological theses, which fall under social sciences and partially the didactic field, should be considerate in the explanations of the school failure as those works allows identifying a whole class of phenomena, which could not by perceived in only one of both frames [10]. If lots of empiric results have emerged from European's' anthropo-didactic research, which releases from social sciences' perspective [2,
25], in Quebec, most scientific publications about learning difficulties adopt cognitive sciences' perspectives. In this context, there is a crying need to test the social science perspective within the Quebec school system [21, 26].

\subsection{Interpretation of Learning Difficulties: Benefits of the Anthropo-didactic Approach}

In the wake of the debates that have taken place in recent years between the proponents of the two main explanatory approaches, a third perspective has emerged from European studies focusing on learning difficulties in mathematics $[1,5$, $6,8,9,27]$. This approach, which comes from the perspective of the social sciences concerning the explanation of learning difficulties, makes it possible to consider the student in the foreground for his cultural affiliations which predict, in part, his place and his expectations within the school institution [26]. This makes it possible to deepen the subject's dispositions in his relationship with knowledge while considering his identity and his history [28]. In order to do this, this perspective proposes to adopt a double theoretical anchor (combining anthropology and didactics) that rely mainly from the social sciences, but by borrowing some postulates, concepts or theories (such as the theory of situations) specific to the didactic perspective. The approach promoted by this third perspective, called anthropo-didactic, is therefore located at the crossroads of two theoretical fields: one didactic which studies the phenomena of teaching by considering the central role played by the structure of mathematical knowledge as well as the modalities concerning teaching and learning [3, 29] and the other, anthropological, which situates its object of study on the cultural dimensions related to the different teaching contexts in which emerge the practices of teachers and students.

This anthropological field makes it possible in particular to consider the cultural background which relates to the process of socialization of an individual throughout his development $[9,30]$. This background is influenced by the "knowledge and beliefs" [31] that teachers have of their students, of their profession, of teaching students with difficulties in mathematics. It influences, unconsciously, the act of teaching [9]. To this end, Lessard [32] highlights the fact that a learner's educational background has a significant influence on the dynamics of teaching and learning difficulties.

One of the explanations of learning difficulties in mathematics provided by adherents to this third perspective is that the educational institution transforms the social classification of students into school classification [3]. In other words, it would transform social class differences into differences in intelligence [33]. Over generations, this mechanism would lead to the upper classes to preserve their privileged status [34]. Moreover, the relevance of considering the anthropo-didactic approach comes from the fact that it makes it possible to identify a whole class of explanatory phenomena of the difficulties which could not be identified in one or the other of the two frameworks (cognitivist perspective and didactic perspective) taken individually. Indeed, learning difficulties can be understood, 
not only in terms of the specificities relating to teaching, knowledge and didactic interactions that take place in the classroom, but also according to the individual characteristics of the student who are possibly influenced by their personal history, their family dynamics as well as by factors linked to their social affiliation [26].

\subsection{Summary of the Postures of the Different Explanatory Perspectives}

In order to describe the perspective adopted by the different disciplines that study learning difficulties in mathematics, Giroux [35] has proposed a scheme for organizing these disciplines according to their purpose or their epistemological posture. As shown in Figure 1, this scheme makes it possible to reflect the purposes of the different disciplines on a transversal axis. On this axis, a shift to the left translates into a growing interest in the study of cognitive functioning and a focus on the characteristics of the student in explaining his difficulties. In addition, a shift to the right of the transverse axis represents a growing interest in the study of the functioning of knowledge in a teaching or learning situation as well as a look at the environmental causes likely to give rise to the difficulties. In light of Giroux's comments [35], it is possible to note that the proponents of the first perspective (cognitive perspective), which notably includes research from developmental psychology, neuropsychology and cognitive sciences, are on the left of the axis. This is justified by the fact that the explanatory framework for learning difficulties adopted by researchers working in this discipline is characterized by a focus on the individual characteristics of students. Moreover, the proponents of the second perspective, underlying the didactics of mathematics, are located at the centre right of the continuum since they centre their object of study in the interactions between the student and the didactic system. Finally, researchers who adopt the third explanatory perspective (social science perspective) position themselves on the far right of the continuum. This is justified by the fact that the proponents associated with this perspective explain the learning difficulties by looking simultaneously at the structure of mathematical knowledge at stake as well as according to the socio-cultural dimensions likely to favour the emergence of these difficulties.

\begin{tabular}{|c|c|c|c|c|c|}
\hline \multicolumn{4}{|c|}{ COGNITIVE PERSPECTIVE } & $\begin{array}{c}\text { DIDACTIC } \\
\text { PERSPECTIVE }\end{array}$ & $\begin{array}{l}\text { SOCIOLOGICAL } \\
\text { PERSPECTIVE }\end{array}$ \\
\hline \multicolumn{3}{|c|}{ Cognitive sciences } & \multirow{2}{*}{$\begin{array}{l}\text { Developmental } \\
\text { psychology }\end{array}$} & \multirow{2}{*}{$\begin{array}{l}\text { Mathematics } \\
\text { didactic }\end{array}$} & \multirow[b]{2}{*}{ Anthropo-didactic } \\
\hline Neuropsychology & $\begin{array}{l}\text { Cognitiv } \\
\text { psycholo }\end{array}$ & & & & \\
\hline $\begin{array}{l}\text { Study of the brain } \\
\text { seat of mental } \\
\text { functions }\end{array}$ & \multicolumn{2}{|c|}{$\begin{array}{c}\text { Study of cognitive } \\
\text { process/knowledge } \\
\text { formation }\end{array}$} & $\begin{array}{c}\text { Study of the kids' } \\
\text { cognitive } \\
\text { development }\end{array}$ & $\begin{array}{l}\text { Study of didactic } \\
\text { conditions }\end{array}$ & $\begin{array}{l}\text { Study of the } \\
\text { making of } \\
\text { educational } \\
\text { inequalities } \\
\text { (non-didactic } \\
\text { conditions) }\end{array}$ \\
\hline \multicolumn{4}{|c|}{$\begin{array}{l}\text { INDIVIDU'S } \\
\text { CHARACTERISTICS }\end{array}$} & \multicolumn{2}{|c|}{$\begin{array}{r}\text { KNOWLEDGE TRANSMISSION } \\
\text { AND ACQUISITION }\end{array}$} \\
\hline \multicolumn{2}{|c|}{$\begin{array}{c}\text { DYSCALCULIA AND } \\
\text { LEARNING DIFFICULTIES }\end{array}$} & & $\begin{array}{l}\text { LEARNING } \\
\text { DIFFICULTIES }\end{array}$ & \multicolumn{2}{|c|}{$\begin{array}{l}\text { (DYS/FUNCTIONING OF } \\
\text { DIDACTIC SYSTEMS }\end{array}$} \\
\hline \multicolumn{2}{|c|}{$\begin{array}{l}\text {-INFORMATION PROCESSING } \\
\text { MECHANISM (SYMBOLS } \\
\text { MANIPULATION) }\end{array}$} & \multicolumn{2}{|c|}{$\begin{array}{l}\text {-KNOWLEDGE } \\
\text { FUNCTIONING IN } \\
\text { SITUATION }\end{array}$} & $\begin{array}{l}\text {-KNOWLEDGE } \\
\text { FUNCTIONING IN } \\
\text { SITUATION }\end{array}$ & $\begin{array}{l}\text {-SCHOOL } \\
\text { CULTURE } \\
\text {-IDEOLOGIES }\end{array}$ \\
\hline \multicolumn{2}{|c|}{-COGNITIVE FUNCTIONING } & \multicolumn{2}{|c|}{$\begin{array}{l}\text {-KNOWLEDGE } \\
\text { TRANSFORMATION }\end{array}$} & $\begin{array}{l}\text {-KNOWLEDGE } \\
\text { SPECIFICITY }\end{array}$ & $\begin{array}{l}\text {-RELATION TO } \\
\text { KNOWLEDGE }\end{array}$ \\
\hline
\end{tabular}

Legend

Line 1: Explicative perspective

Line 2: Discipline

Line 3: Study's object

Line 4: Continuum on which the disciplines are positioned in function of there finality

Line 5: Terminology, main concepts used

Line 6: Explicative avenues of mathematics capacity

Figure 1. Adaptation of Giroux's schema which concerns the organization of disciplines who study the learning difficulties according to Giroux [35]. 
The general objective of the study is to explore how the three explanatory perspectives of learning difficulties that have been presented are revealed into the interpretations of professionals in the education when they position themselves in terms of the nature of the learning difficulties as well as the methods used to screen for them.

Moreover, to our knowledge, no study has documented the way in which the anthropo-didactic approach, which comes from the perspective of the social sciences, manifests itself in the comments of professionals in education of Quebec when the interpret and do the screening of learning difficulties in mathematics. From this observation, a specific research objective emerged. In fact, this study also aims to document how the explanatory thesis underlying the anthropo-didactic approach is found in the types of interpretation made by professionals concerning the difficulties of their students. This process is carried out with the aim of verifying whether the consideration of these difficulties generates a complementary contribution to the two traditional explanatory perspectives.

\section{Methodology}

\subsection{Research Design}

To achieve our research objective, we implemented a qualitative design allowing the study and interpretation of the phenomenon of learning difficulties in mathematics in the school environment. To do this, we have relied on the meanings and descriptions that educational professionals attribute to these difficulties. Indeed, the chosen method aims above all to explore and describe a phenomenon from the point of view of the participants in order to understand its meaning [36]. To do this, we analyzed the discourse of educational professionals regarding their interpretation of learning difficulties in mathematics as well as the methods of screening for these difficulties with Quebec students enrolled in elementary school. The aim of this research is not directly practical. Its contribution relates rather to existing knowledge [36, 37].

\subsection{Data Collection}

Since the objective of the research was to study the perceptions of educational professionals on the research issue, semi-structured interviews were chosen as a data collection tool. During these interviews, we used an interview guide in which we had a series of questions relating to four distinct themes, namely:

1) The interpretation of learning difficulties (4 questions);

2) Screening for learning difficulties (7 questions);

3) Carrying out a diagnosis (8 questions);

4) Educational intervention with students in difficulty (8 questions).

It is important to mention that the interview guide included other sections to establish the socio-professional profile of the participants as well as to describe the nature of the professional experiences lived with the students characterized as having learning difficulties in mathematics.

Verbal exchanges between the researcher and the participants were recorded. All interviews were identified by a number in order to preserve the anonymity of the participants. Then, the audio files were transcribed in the form of verbatim. The recordings and verbatim were listened to and read several times in order to allow a deep understanding of the meaning of the participants' statements and to identify specific meanings [38]. All of the data from the research was co-analyzed by two research assistants.

\subsection{Participants}

Our sample consists of eight elementary school teachers and six education professionals (three orthopedaguans and three pedagogical advisers working in elementary school) from the Quebec City and Abitibi-Temiscamingue regions. Table 1 shows the coding used to ensure the anonymity of the participants.

Table 1. Codification of participants.

\begin{tabular}{ll} 
Professional status and place of residence of participants & Educational advisers Numeric code of participants \\
\hline $\begin{array}{l}\text { Teachers from Quebec region } \\
\text { Teachers from Abitibi-Temiscamingue }\end{array}$ & Informants $\mathrm{n}^{\circ} 01,02,03,04,05$ \\
$\begin{array}{l}\text { Professionals form Quebec region } \\
\text { Orthopedaguans }\end{array}$ & Informants $\mathrm{n}^{\circ} 06,07,08$ \\
$\begin{array}{l}\text { Pedagogical advisers } \\
\text { Professionals form Abitibi-Temiscamingue }\end{array}$ & Informants $\mathrm{n}^{\circ} 09,10$ \\
$\begin{array}{l}\text { Orthopedaguans } \\
\text { Pedagogical advisers }\end{array}$ & Informant $\mathrm{n}^{\circ} 12$ \\
\hline
\end{tabular}

On average, the teachers were 33 years old and had 11 years of experience. For their part, education professionals had an average of 39 years and 15 years of experience.

\subsection{Data Analysis}

In order to analyze the data from this research, a discourse analysis was performed [39]. This type of analysis makes it possible to describe and explain a phenomenon by discovering themes, categories and reference models. It was therefore through a discursive process of reformulating and explaining interviews that the data were analyzed, organized and processed, so that they could help to better describe and understand the phenomenon [37].

The data analysis was characterized as a deliberate inductive type. It was carried out with reference to the different phases proposed by L'Ecuyer [40]. This analysis was deliberate since the frame of reference already offers 
some preconstructed categorization as well as inductive to the fact that some emerging categories were induced by the data collected. Data encoding was done through NVivo software. Referring to Deslauriers [41], the inductive process of data analysis was initiated by the implementation of a detailed description of the different methods of interpreting learning difficulties as formulated by a group of education professionals. At the end of this in-depth analysis, it was possible to extract significant properties from the discourse of the study participants and separate them in groups of main themes. As mentioned by Miles and Huberman [42], this analytical approach has made it possible to study the phenomenon of the interpretation and detection of learning difficulties in mathematics from its fundamental components.

\section{Results}

\subsection{Nature of Learning Difficulties in Mathematics}

After questioning the participants in order to characterize the fundamental nature of learning difficulties, all of the response elements were grouped together to bring out the following four main themes:

1. Explanatory factors relating to mathematical knowledge;

2. Explanatory factors relating to the cognitive functions of the student;

3. Explanatory factors relating to teaching method;

4. Explanatory factors relating to the social context of the learner.

Among these themes, some were mentioned by a greater number of participants. For each of the major themes, Figure 2 allows us to establish the frequency of comments reported by the participants.

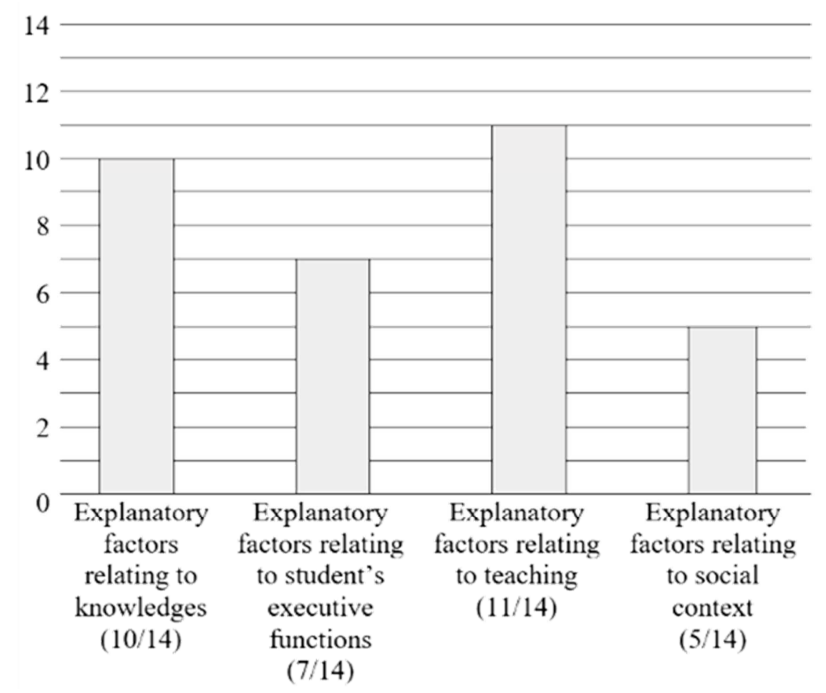

Figure 2. Explanatory factors for learning difficulties in mathematics and response frequencies.

We observe that the themes whose explanatory factors relate to teaching $(11 / 14)$ and mathematical knowledge (10/14) were each raised by more than two thirds of the participants in order to explain the origin of the main difficulties in mathematics. Then comes the theme which attributes the learning difficulties to the student and more precisely to the cognitive functions intrinsic to the student. This theme is raised by half of the participants (7/14). Finally, for five participants out of the 14 questioned, learning difficulties in mathematics can also be explained through social variables.

The various themes identified will be explored successively in the following sections, starting with the one addressed by the greatest number of respondents. In order to detail the vision of the participants regarding the nature of these difficulties, different sub-themes that emerged from the answers will be presented.

\subsubsection{Explanatory Factors for Difficulties Relating to Teaching Methods (11 Respondents out of 14)}

Three main sub-themes emerge from the comments of the participants, which identify the possible factors of difficulties in the teaching provided at school. In correspondence with their order of importance according to the number of elements of answers provided during the interviews, they are presented consecutively:

1. Concrete manipulation activities;

2. Teaching methods;

3. Curriculum and training program.

First, for seven participants, the learning difficulties in mathematics related to teaching methods are attributable to deficiencies in concrete manipulation activities. Indeed, a respondent states that concrete manipulation activities are not sufficiently implemented in the school environment: "It is underused [...] often, this part is overlooked" (informant no. 12). Another participant adds: "The teachers go too quickly from addition to subtraction, then to multiplication, instead of making people understand, of making them manipulate" (informant $\mathrm{n}^{\circ} 11$ ). A last respondent explains that we must "go beyond the traditional stage of paper / pencil [...] They must be handled, to allow them to dissect and make them understand before falling into an exerciser" (informant $\mathrm{n}^{\circ} 01$ ).

In addition to the shortcomings arising from the manipulation activities, some participants (3/11) broached as a second subtheme the learning difficulties linked to teaching methods. According to them, the difficulty in identifying a precise teaching method arises from the context of problem-solving: "In problem-solving, the fact of not giving a line of conduct, of not having a school-based method creates a problem" (informant $\mathrm{n}^{\circ} 05$ ). Another participant mentions that "the problem-solving is used as an evaluation and not as a lever for learning [...] That is a big problem especially for the SHSMLD" (informant $\mathrm{n}^{\circ} 10$ ).

The last subject dealt with concerns the school curriculum and the training program. Two participants are of the opinion that this one is "too big," "too difficult" (informant $n^{\circ} 9$ ), or even, poorly adapted:

You have to go quickly, always too fast [...] The principals even ask us to adapt the teaching material, because the requirements are too high for the level taught. It creates a burden for the teacher who continues to want to go fast in order to see the whole program (informant $n^{\circ} 08$ ). 
Other responses include too many assessments and reading difficulties that affect math achievement.
Table 2 provides a brief summary of the main factors described above.

Table 2. Factors explaining the difficulties relating to teaching.

\begin{tabular}{ll}
\hline Sub-themes & Main factors \\
\hline Concrete manipulation activities & Lack of manipulation to grasp the meaning of certain mathematical concepts; \\
& Lack of concrete manipulation activities. \\
Teaching methods & Lack of clear and consensual procedures for teaching problem-solving; \\
& Importance of consistency, clear instructions and a variety of materials. \\
Curriculum and training program & Program too busy and poorly adapted. Consequence: teachers have to go fast; \\
& Too many evaluations.
\end{tabular}

Looking further into the data from the respondents' discourses, it is possible to note that the most frequently discussed theme concerning the explanation of the nature of learning difficulties in mathematics relates mainly to the didactic perspective. Moreover, one observation emerges from the main explanatory factors of the difficulties relating to teaching methods. In fact, the explanatory avenues put forward stem from external constraints underlying teaching (for example, the constraints associated with the training program, a reduction in didactic time given the quantity of evaluations to be carried out as well as the lack of institutional guidelines to teach problem-solving are extrinsic factors to professionals). This finding is surprising since the international scale, as at the provincial level, scientific writing documents the low feeling of competence of educators concerning the teaching of mathematics [43, 44], which represent intrinsic factor specifics to elementary teachers.

\subsubsection{Explanatory Factors Relating to the Nature of Knowledge (10 Respondents out of 14)}

The second major theme allows us to consider the explanatory factors of learning difficulties in mathematics in relation to the nature of knowledge. Like the previous theme, three sub-themes emerge from the participants' comments. Referring to the frequency of responses, these are presented in their respective order of importance:

1. Partial understanding of basic knowledge;

2. Number sense;

3. Difficulties associated with problem-solving.

Regarding the main theme linking learning difficulties to mathematical knowledge, half of the answers proposed by the participants are related to the partial understanding of basic knowledge. Several participants (6/10) are indeed worried about the "lack of solid foundations of mathematical concepts" (informant $\mathrm{n}^{\circ}$ 01) and some attribute this problem to the accelerated pace from which they must teach: "The students pass too quickly on the learning [...], then it creates difficulties, for example, sixth grade students who do not know when to add" (informant $\mathrm{n}^{\circ} 08$ ). When asked about the nature of the concepts for which the students demonstrate a partial understanding of basic knowledge, the participants name the fractions ("It's always difficult" [informant $n^{\circ} 01$ ]) and the multiplicative structures ("This is really what is most lacking" [informant $\left.n^{\circ} 10\right]$ ). Finally, two participants stated the difficulties in understanding the act of grouping in base 10 system. One of them deepens his remarks by explaining himself as follows: "The system in base 10 is not there [...] The representation of the number is at the base of the problem" (informant $\mathrm{n}^{\circ} 12$ ).

The remaining answers are split between the following two topics: number sense (addressed by four participants) and problem-solving (underlined by three respondents). First of all, by "number sense," one participant means "the flexibility and fluidity to imagine and manipulate numbers" (informant \# 14). According to him, many students do not develop this understanding until they operate with numbers. Another participant adds: "The pupils do not understand well the meaning and the different forms of writing of the same number, for example whole numbers, fractions, decimals" (informant 03).

In the last subtheme, the difficulties are associated with the knowledge involved in the problem-solving. This subtheme addresses two main ideas. According to one participant, the students have difficulty justifying their approach: "In problem-solving, as soon as you reach the justification phase, that's where you lose them" (informant no. 05). For another participant, the learning difficulties are attributable to the language factor involved in the problem-solving statements which contain too many words: "The student must then succeed in reading the situation [...] When the problem is not that complicated, it is already a challenge. So it is French that comes into play" (informant $n^{\circ}$ 03). Another participant mentions the difficulties in problem-solving underlying the linguistic aspect: "In solving, the students must select the information worked on in French and then transferred to math [...] it can be very difficult» (informant $n^{\circ} 01$ ).

Table 3 provides a brief summary of the main factors discussed in the previous paragraphs.

Table 3. Explanatory factors relating to mathematical knowledge.

\begin{tabular}{ll}
\hline Sub-themes & Main factors \\
\hline Partial understanding of basic knowledge & $\begin{array}{l}\text { Partial understanding of certain mathematical concepts (fractions, measure, multiplication rules, numeration). } \\
\text { Lack of flexibility and fluidity in thinking numbers; }\end{array}$ \\
Number sense & Poor understanding of the meaning and representation of numbers (natural numbers, fractions, etc.); \\
& Lack of understanding of the meaning of certain basic operations (grouping in base 10, multiplicative structures). \\
Difficulties associated with & Difficulties at the justification process; \\
problem-solving & Difficulties in reading comprehension.
\end{tabular}


The analysis of the data made it possible to highlight various explanatory factors for the learning difficulties relating to mathematical knowledge. As mentioned by Mazzocco and Thompson [45], a misunderstanding of number sense can later lead to difficulties in learning various mathematical concepts promoted within the school curriculum. In this regard, we see that the respondents to the study consider that the explanatory factors of learning difficulties relating to mathematical knowledge are mainly associated with the field of arithmetic as well as problem-solving activity. This finding is not surprising since most of the time, the didactic dedicated to the teaching of mathematics aims at the learning of concepts and processes from the field of arithmetic as well as the implementation of problem-solving activities. In addition, this situation makes it possible to identify an undervaluation of other domains of mathematics in the explanation of the difficulties experienced within elementary school (geometry, measurement, probabilities and statistics).

\subsubsection{Explanatory Factors Relating to the Cognitive Functions Intrinsic to the Student (7 Respondents out of 14)}

The third major theme discussed by respondents mentions that the learning difficulties in mathematics are attributable to the cognitive functions of the students. Two sub-themes are identified. These are presented in their respective order of importance:

1. Cognitive limitations in the context of problem-solving;

2. Cognitive limitations regarding memory and abstraction capacity.
Regarding the main theme linking learning difficulties in mathematics to the cognitive functions of the student, six participants raised the specific subject of cognitive limitations in the context of problem-solving. For these respondents, the difficulties come from the organization and planning as implemented by the students: "In resolution, we explain to them the structure to follow, but it is difficult to make them understand $[\ldots]$ we show the tree, the grocery list $[\ldots]$ but it's still hard "(informant $\mathrm{n}^{\circ}$ 01). Another participant adds: "They are able to get out the important information, to get out the mathematical terms $(+,-$, etc.) but then it blocks in problem-solving" (informant $\mathrm{n}^{\circ} 05$ ).

Subsequently, three participants made comments relating to another subtheme of difficulties that are related to the cognitive functions of students. According to these participants, cognitive limitations regarding memory and abstraction capacity can be considered in order to explain the difficulties of the students. A participant commented that for some students, "Memorization is more difficult. We can say that we no longer want to be fair about the retention of procedures, but a student who does not memorize anything, it is sure that it is difficult" (informant $n^{\circ} 12$ ). For another participant, the difficulties come from the capacity for abstraction: "There are students who have difficulty making connections between mathematical concepts [...], mental imagery and abstraction are much more difficult" (informant $n^{\circ}$ 09).

Table 4 provides a brief summary of the main responses highlighted in the previous paragraphs.

Table 4. Explanatory factors relating to the cognitive functions intrinsic of the student.

\begin{tabular}{ll}
\hline Sub-themes & Main factors \\
\hline \multirow{2}{*}{ Cognitive limitations in the context of problem-solving } & Difficulties in organizing, planning, selecting information; \\
& Difficulties in reading comprehension. \\
Cognitive limitations regarding memory and abstraction capacity & Difficulty memorizing the process to follow to solve a mathematical problem; \\
\hline
\end{tabular}

The explanatory factors related to cognitive functions in order to interpret learning difficulties are mainly associated to scientific writings specific to the field of cognitive psychology. Moreover, by referring to the work of Barrouillet [46], we show that the respondents did not directly address the track of the limitations associated with visuospatial skills, a subtype of difficulties documented by cognitive researchers (in addition to the subtypes limitations that relate to memory and cognitive functions). This observation leads us to think that in the Quebec Province, education professionals focus on the field of arithmetic and on the student's ability to solve problems in order to explain students' difficulties in mathematics. However, the consequences of this centration can result in an under-valuation of the geometrical and spatial knowledge of the students in the explanation of their difficulties.

\subsubsection{Explanatory Factors Relating to the Student's Social Context (5 out of 14 Respondents)}

In order to document the role of the learner's environment on the level of success of the learner, the last major theme raised highlights the factors associated with the social context of the student. Three subthemes emerged from the comments of the participants. These are presented in their respective order of importance:

1. Family environment;

2. Social expectations and self-perception;

3. Lifestyle habits.

First, for three participants, learning difficulties in mathematics may be attributable to the student's family environment. A participant explains that several difficulties can come from an undervaluation of homework and study: "Without throwing all the blame on the parents, I think this is an important factor" (informant \# 02). Lack of family support can also cause anxiety and thus lead to learning difficulties. This observation is put forward by another participant: "Depending on the subject, it's not all the families of the students in my class that support their children. They are not there for them. It is a sad observation 
and it plays in the balance when it comes to learning difficulties" (informant $n^{\circ} 08$ ). A third participant underlines "lack of stimulation at home", for example, the fact that "parents play less, or not at all, board games with their children" (informant $\mathrm{n}^{\circ} 14$ ). For him, it is a social phenomenon that can have significant consequences on the educational success of some students.

Another subtheme tackled by two participants is that of social expectations and its impact on the self-perception of certain learners: "The students give themselves a role very early in their course, either: good or bad in math, in French [...] then, it becomes the basis of the conception that the students have of themselves" (informant $n^{\circ} 02$ ). Another participant mention that there is a "sort of Pygmalion effect of the social factor on the role that students play of themselves [...] for example, many believe that girls are less good at math [...] that creates trust problems" (informant $\mathrm{n}^{\circ} 03$ ).

The last subtheme concerns certain lifestyle habits of young people. This was raised by a single participant. Indeed, according to one respondent, learning difficulties can be explained in particular by a lack of rest, by the "super busy schedule" of the students as well as the constant exposure of the students to digital devices ("too many screens and too much TV") (informant $n^{\circ} 04$ ).

Table 5 provides a brief summary of the main explanatory factors highlighted in the previous paragraphs.

Table 5. Explanatory factors relating to the student's social context.

\begin{tabular}{ll}
\hline Sub-themes & Main factors \\
\hline & Undervaluation of homework and study; \\
Family environment & Lack of support from parents; \\
& Lack of stimulation at home. \\
Social expectations and self-perception & Some students' biased conception of their ability to succeed in mathematics; \\
& Pygmalion effect concerning the performance of girls in mathematics. \\
Lifestyle habits & Busy schedule; \\
& Constant exposure to digital devices (telephone, television, etc.). \\
\hline
\end{tabular}

A view of the explanatory factors relating to the social context of the student concerning the explanation of learning difficulties highlight the predominant role of parents to support the student scholarship. By avoiding explaining difficulty by the role of heritability as documented by scientific literature, educational professionals are moving away from the cognitivist perspective of interpreting learning difficulties. The discourses reported rather focus on the role of the professional skills of teachers, particularly with regard to collaboration with parents and the school team.

\subsection{Screening the Learning Difficulties in Mathematics}

In addition to documenting the main explanatory factors underlying the interpretation of learning difficulties in mathematics, this study also explored the theme of screening for these difficulties. To this end, the following two sections make it possible to present, in the form of frequencies, the main instruments used by education professionals to screen for students with learning difficulties in mathematics as well as the professional identified as being responsible for screening in each of the school environment. Finally, referring to the analysis of the discourses of the respondents, the last part of this section focus on the characteristics of the students perceived as being most at risk of being diagnosed within screening activities.

\subsubsection{Instruments used for Screening the Learning Difficulties in Mathematics}

Participants were asked about the main screening instruments used with students who have learning difficulties in mathematics. The analysis of the interviews made it possible to identify certain instruments used either by teachers or by education professionals. Among the instruments identified, we note: the observation grid, the interview, math games, standardized instruments, routine exercises or even instruments from the respondents' home school board.

Table 6 presents, in order of importance, the frequency with which respondents mentioned using an instrument to screen for learning difficulties in mathematics of the elementary school students. The presentation of the results considers their professional status of the respondent.

Table 6. Screening tools used, in order of importance and according to respondent status.

\begin{tabular}{llll}
\hline Screening instrument & Number of respondents & Number of teachers & Number of educational professionals \\
\hline Interview & 10 & $6($ no 01, 02, 03, 04, 07, 08) & $4($ no 09, 10, 11, 12) \\
Observation grid & 7 & $4($ no 01, 03, 07, 08) & $3($ no 09, 10, 11) \\
Instruments from the school board & 5 & 2 (no 04, 05) & $3($ no 11, 12, 13) \\
Standardized assessment instrument & 4 & 1 (no 05) & $3($ no 09, 10, 11) \\
Math games & 3 & 1 (no 03) & $2($ no 09, 10) \\
Personal assessment instruments & 3 & $3($ no 02, 03, 06) & - \\
Formative assessments & 3 & 2 (no 04, 06) & 1 (no 10) \\
Exercises & 3 & 1 (no 07) & 2 (no 09, 10) \\
\hline
\end{tabular}

Note: Among the instruments of screening identified by two or more respondents, we find the questions asked by the students (2), the small school works (2), drawing activities (2), the task cards (1), the variation of the contexts (1), the daily observations (1), the analysis of student mathematical errors (1) and the instruments built with the teachers in the context of codevelopment (1). 
All participants identify at least one instrument for identifying learning difficulties in mathematics. As can be seen in the table above, the interview is the most used screening instrument by respondents. Six teachers and four professionals mentioned using this instrument. The observation grid is also a screening instrument considered by the participants, particularly among orthopedaguans (the three orthopedaguans interviewed mentioned using this instrument) The tools produced or provided by the school board are used by two teachers, three oethopedaguans and an pedagogical advisor.

As for the standardized instruments (Keymath and Prime), these are used by three orthopedaguans and one teacher. Three respondents use math games to identify students with mathematical difficulties. Finally, an orthopedaguan points out that self-assessment can be used to screen students enrolled in high school.

\subsubsection{Identification of Professionals Responsible for Screening}

A consensus emerges from respondents' comments regarding the identification of the professional responsible for screening students with difficulties in mathematics. Indeed, 12 out of 14 participants identify the elementary school teacher as the principal resource responsible for the screening activity. In addition, two respondents consider that it is the orthopedaguans who are responsible for screening.

Specifically, seven of the eight teachers name the teacher as the principal responsible for identifying learning difficulties in mathematics. It is important to mention that only one teacher identifies the orthopedaguan as first responsible for this professional task. For education professionals, a orthopedaguan identifies himself as being principally responsible for screening (this respondent adds that the teacher has a support role in order to realize this task), while five of the six professionals identify the teacher as the main responsible for the screening.

\subsubsection{Characteristics of the Groups of Students Most at Risk}

According to participants, some students from a particular population are more at risk than others of being identified as students with learning difficulties in mathematics, even before starting the screening task. In this regard, the analysis of the respondents' speech made it possible to identify seven characteristics of learners that are likely to influence the professional's activity when screening for learning difficulties in mathematics: gender, immigration status (first or second generation immigrants), presence of a second diagnosis, socioeconomic class, parental education, parental support and self-esteem.

Table 7 presents, in order of importance, the frequency with which respondents mentioned characteristics that make it possible to target students when screening for learning difficulties in mathematics in elementary school.

In light of the responses of the participants, we observe a range of socio-cultural factors that may influence the screening activity of students with learning difficulties in mathematics. In fact, five of the seven characteristics that were identified relate to sociocultural factors (with the exception of self-esteem and the presence of a concomitant diagnosis). These will be detailed successively according to the frequency with which they were considered in the comments of the respondents.

Table 7. Characteristics to consider when screening for students with learning difficulties in mathematics.

\begin{tabular}{ll}
\hline Characteristics & Number of participants \\
\hline Low parental support & 13 \\
Parents' education & 11 \\
Socioeconomic class & 11 \\
Poor self-esteem & 9 \\
Gender & 5 \\
Ethnocultural origin & 5 \\
Diagnosis concomitant with learning & 5 \\
difficulties in mathematics (ADHD, etc.) & \\
\hline
\end{tabular}

First, the quality of parental support ranks first among the characteristics that make it possible to target a student before initiating the screening activity (13 out of 14 respondents) of learning difficulties in mathematics. A consensus emerges from the comments put forward by the participants to this effect: "This is major" (informant $\mathrm{n}^{\circ} 02$ ), "It is very important" (informants' $\mathrm{n}^{\circ}$ 01, 06, 10 and 11). A participant explains: "The lack of support and stimulation at home can cause difficulties of all kinds in terms of supervision, but also motivation" (informant 02). In contrast, positive parental support can become a protective factor: "Valuing the child's efforts, not just putting a signature at the bottom of an exam can make a big difference"(informant 08).

Still in the field of sociocultural factors, the second characteristic considered to be the most decisive in targeting a student in difficulty during screening refer to the parents' education (11 respondents). For these participants, this characteristic is frequently observed among students with learning difficulties in mathematics when the parents, especially the mother, have a low level of education. A participant points out that:

Many studies show that a mother's education is a factor in predicting academic success [...] The dropout mother has a huge impact on her children [...] children, for example, are more likely to have reading difficulties due to lack of exposure, etc. (informant $n^{\circ} 12$ ).

These comments are further explored by another respondent: "I think that in general, the more parents are educated, the more they are going to want the children to perform well in school as well" (informant 03). Regarding the education of parents, some participants add nuances, citing the example of parents with little education who value school and support their child.

With regard to the characteristic of socioeconomic class, participants mentioned a link with learning difficulties (11 respondents). A participant shares his experience by saying that "the socioeconomic class seems to have a great effect" (informant $n^{\circ} 03$ ), while another respondent specifies his thoughts concerning students from disadvantaged 
backgrounds: "These students are no less intelligent, it is rather than depending on the place, some children have less stimulation" (informant $n^{\circ} 12$ ).

Then, the last two sociocultural characteristics (gender and ethnocultural origin) are mentioned by almost a third of the participants. Discussing of gender influence, five participants consider that girls are more at risk of being identified as having a learning difficulty. A participant explains his remarks as follows: "The social impact is being felt [...] I have the impression that it will have a negative impact on the girls who will say to themselves: a girl is less good in mathematics therefore, it is normal if I have difficulty" (informant $n^{\circ} 03$ ).

Regarding the factor associated with ethnocultural origin, participants who mentioned an association with learning difficulties in mathematics ( 5 respondents) consider that this mainly relates to language: "I would say that it is especially at the level of the language barrier that it can have an impact, when a student has francization needs" (informant $n^{\circ} 04$ ). Another participant adds: "Language creates difficulties in mathematics, especially in problem solving" (informant 05).

In addition, nearly two thirds of participants ( 9 respondents) consider that poor self-esteem plays a role in the emergence of learning difficulties in mathematics among elementary school students. One participant explained that "a child with high esteem will try will raise his hand, while a child with low esteem tries less and sometimes accumulate delays" (informant 05). Another participant adds that "in general, the relation to the self-perception of the students seems to have a major impact, especially on the girls" (informant $n^{\circ} 04$ ). To this end, it is important to mention that this factor, of an affective nature, relates to the intrinsic characteristics of the student.

Finally, it is important to emphasize that the presence of a concomitant diagnosis, such as attention deficit disorder with or without hyperactivity (ADHD), autism spectrum disorder, language disorders as well as non-verbal dysfunction syndrome, can make it easier to target students in difficulty during the screening activity. This last characteristic, which makes screening easier, is closely linked to the cognitive functions that are intrinsic to the learner (informant $n^{\circ} 1,03$, $10,11,13)$.

In the light of the analysis of the respondents' discourse, it is possible to observe that education professionals mainly refer to the perspective of the social sciences to target groups of students at risk of being identified during the screening activity. Our results show that the main characteristics to be considered during screening relate to socio-demographic factors. To interpret this finding, we hypothesize that the respondents' comments relate mainly to their professional experience (on average 11 years of experience for teachers and 15 years of experience for professionals) rather than to the knowledge obtained from their university education. Otherwise, if the respondents had referred to the knowledge resulting from their academic training, this would have mainly proposed characteristics relating to the diagnostic manuals used in the school environment. For example, the DSM-V: Diagnostic and Statistical Manual of Mental Disorders [47] mentions the following risk factors for the emergence of learning disabilities (persistent difficulties) in mathematics: genetics, gender as well as the various concomitant disorders likely to interfere with the quality of learning.

\section{Summary of Results and Discussion}

\subsection{Various Explanations Concerning the Nature of Learning Difficulties in Mathematics}

In light of the data obtained, four main themes emerge from the participants' comments regarding their interpretation of the nature of learning difficulties in mathematics. The first explanation of learning difficulties emanates from factors underlying teaching. Essentially, respondents argued that students' difficulties in mathematics stems from deficiencies in manipulative activities that make it difficult for students to make sense of certain concepts in mathematics. In addition, the teaching methods, sometimes ineffective in teaching a specific concept, as well as the school curriculum in place contribute to undervaluing certain portions of the mathematics training program. This may possibly cause difficulties in the acquisition of knowledge in mathematics.

Then, the second major theme that emerged from the data analysis links the foundations of learning difficulties in mathematics to the nature of knowledge. In this regard, the elements of the speeches of the participants relating mainly to this major theme suggest that the students' difficulties are mainly explained by a partial understanding of mathematical knowledge which is the basis of a hierarchy of concepts which gradually progress in complexity. In addition, according to the participants, the acquisition of the sense of numbers as well as the difficulties felt by some students concerning the requirements of mobilizing mathematical knowledge in the context of problem solving constitute significant avenues for explaining the fundamental nature of the students' difficulties in mathematics.

It is important to mention that the first two major themes highlighted by our analysis concerning the explanation of the foundations of learning difficulties relate mainly to the explanatory perspective of didactics. Indeed, the elements of speech of these two major themes essentially attribute the nature of the learning difficulties to the functioning of the didactic system as well as the specificity of the knowledge underlying the tasks in mathematics. In addition, it should also be noted that the third and fourth major themes that emerged from our analysis concerning the explanation of the nature of learning difficulties relates to the two other explanatory perspectives (cognitive and social sciences).

Indeed, the third major theme that emerged from the data analysis attributes students' difficulties in mathematics to the cognitive functions. In this regard, the inability of students to memorize, organize and select relevant information within a task explains their poor performance in mathematics. By referring to the comments of the respondents, these cognitive dysfunctions are observed in particular in the problem-solving activity as well as in the students' ability to model a task in mathematics. The explanatory factors of this major theme relate 
directly to the perspective of cognitive science since learning difficulties are interpreted from factors intrinsic to the student.

Finally, the fourth major theme that emerged from the project comes from the comments of respondents who attribute learning difficulties in mathematics to the social context of the students. Within this position, learning difficulties are not considered at an angle of the intrinsic characteristics of the learner, but rather through a look at the environment of the learner (with reference to the mesosystem, as proposed by Bronfenbrenner's theory of human development ecology [48]). In fact, some education professionals consider that the difficulties can be explained primarily by the student's family environment as well as by the parental support offered in carrying out various school tasks. In addition, the social expectations as well as the lifestyles of the students represent other factors to be considered in order to explain the context in which learning difficulties emerge. These statements relate directly to the social science perspective on the explanation of difficulties in mathematics since student performance in this academic discipline is viewed through factors underlying the student's environment.

\subsection{Firm But Fluctuating Positions}

An in-depth look at the results of this research highlight on a firm and definitive stance in the words of education professionals when they position themselves on the nature of students' learning difficulties in mathematics. Moreover, although the positioning of professionals is categorical, we note that the same professional can justify his vision of the nature of learning difficulties by simultaneously referring to explanatory perspectives relating to cognitive sciences, didactics as well as social sciences. The explanation thus formulated is influenced by the cultural background of these workers [9] and is based on an amalgamation of previous experiences resulting from their socialization, their professional practice as well as their initial training.

The diversity of the major themes identified and the nature underlying them lead us to think that it would be possible to make connections between the methods of interpreting learning difficulties in mathematics and the theoretical model of the handicap production process (HPP) (Processus de production $d u$ handicap) developed by anthropologist Fougeyrollas et al. [49]. Indeed, this model proposes to consider the disability of an individual through a constant interaction involving personal and environmental factors (micropersonal, masocommunity and mesosocietal). The complexity underlying the interpretation of learning difficulties in mathematics could perhaps call for the implementation of a similar theoretical model allowing a variety of factors to be taken in consideration.

Moreover, while waiting for a theoretical model to consider this diversity of factors, it is also possible for the researcher to implement a multi-level methodological design inspired by the work of Roine [25]. By carrying out, in a sequential manner, in-depth and independent analyzes on each of the different factors specific to a complex phenomenon, such as the study of the learning difficulties in mathematics of elementary school students, it is possible to consider merging the analyzes in this way.

\subsection{A vision of Learning Difficulties That Breaks with Screening Practices}

Analysis of teachers' discourse on screening procedures highlights findings that are relevant from the research standpoint. Indeed, the data analysis made it possible to document the main instruments used and the professionals responsible for screening in different school settings. In addition, it is important to mention that the majority of respondents distance themselves from their own position when explaining the nature of the learning difficulties when they mention their point of view on populations at risk of being diagnosed with learning disabilities in mathematics. This situation is explained by the fact that only one grouping of characteristics (sociocultural factors) emerged from the comments of the participants when they took a position on the nature of learning difficulties in mathematics. Moreover, when they discussed the screening for learning difficulties, respondents highlighted a range of socio-cultural factors that help identify students at risk in terms of learning in mathematics: the quality of parental support, the level of parents' education, socioeconomic class, gender as well as ethnocultural origin.

As mentioned by Giroux [3], the complexity of learning difficulties in mathematics is such important that it requires the use of theoretical frameworks from the field of social sciences. Moreover, considering the different sections of the interviews, we are surprised to notice a rupture in the discourse of the interviewed participants. Indeed, we anticipated a linkage in the comments of the participants concerning the explanatory perspective of the learning difficulties on which they rely in order to explain the fundamental nature of these difficulties as well as the perspective used for screening populations at risk.

However, the results of the project highlights disparities in the comments of the respondents when they position themselves on the interpretation and detection of learning difficulties in mathematics. This is mainly justified by the fact that many participants argue, first of all, that learning difficulties should primarily be considered through modalities relating to teaching, mathematical knowledge as well as the cognitive functions of the learner. However, they then mention that the populations to be prioritized during screening should ideally be identified through sociocultural factors, without referring to the nature of the difficulties that was announced upstream. To interpret this finding, we hypothesize that education professionals are able to take a position on the fundamental nature of difficulties in mathematics, relying mainly on the discourse of specialists in the field as well as on-acquired knowledge resulting from their academic progress. However, when these participants are questioned in relation to the populations at risk of being diagnosed at the end of the screening activity, they essentially refer to their empirical experience in the teaching and suggest relating to the sociocultural factors to identify students with learning difficulties in mathematics. 


\subsection{The Contribution of the Anthropo-didactic Approach to the Interpretation and Screening of Learning Difficulties}

In the light of the results obtained, we note that the interpretation and screening of learning difficulties in mathematics by education professionals among elementary school students can hardly be achieved by referring exclusively to explanatory frameworks relating to cognitive science and the didactics of mathematics. From this perspective, we mention the relevance of adopting a complementary point of view, relying on the anthropo-didactic approach, in order to deal with sociocultural variables in the explanation of students' difficulties in mathematics. Results of this research suggest that teacher have a "cultural background" which is influenced by their knowledge and beliefs [31] about their work with students in difficulties.

In order to understand how professionals in education interpret and identify learning difficulties in mathematics, a look at this cultural background is highly relevant for the educational researcher. In fact, testing the anthropo-didactic approach has made it possible to document a range of factors likely to influence the nature of the interventions and interactions that these professionals maintain with students in difficulty. The sociocultural factors identified come from different types, such as the family structure, ethnic origin, socioeconomic level, gender, social expectations with regard to the student as well as the presence of technological tools in learning processes. These factors should be taken in consideration in studying the methods of interpreting learning difficulties in mathematics at the elementary school.

In research, the contribution of the anthropo-didactic approach also emerges from the comments of the participants regarding the screening of students in difficulty. Indeed, the study made it possible to highlight on a second range of extracurricular sociocultural factors, linked principally to the social context and to the student's home environment, which influences the process of identifying at-risk students in mathematics. The consideration of this set of sociocultural factors is not negligible since it is likely to modulate educational interventions throughout the scholarship of a learner perceived as being in difficulty. In subsequent research, it would be relevant to carry out an extension of the study of Cherel [50] in order to observe whether the didactic contract is differentiated according to the socio-cultural characteristics associated with a specific group of learners.

\section{Limits to Consider}

It is important to mention that certain modalities associated with the operationalization of the research may have contributed to altering the results of the project as well as their interpretation. Indeed, since the research assistants who worked as interviewers knew the object and aims of this study, it is possible that the conduct of the interview was altered. More specifically, this observation is reflected in the fact that the adaptive component, specific to semi-structured interviews, led interviewers to ask for further study when the respondents formulated remarks relating to the perspective of the social sciences concerning the interpretation of learning difficulties.

This is reflected in particular in the discourse related to the screening activity of education professionals and the identification of populations at risk of being characterized as having learning difficulties in mathematics. Indeed, during the interviews, the interviewers had a list of individual characteristics that would fuel the discussions and deepen the respondents' comments on this topic. Consequently, it is possible that the assistants' knowledge of the research subject contributed to further documenting the sociocultural factors likely to intervene in the screening of students characterized as being at risk to receive a diagnostic of learning difficulties in mathematics.

\section{Conclusion}

This study aimed to explore how the three different explanatory perspectives of learning difficulties in mathematics presented upstream are reflected in the discourses and interpretations of education professionals when they position themselves on the nature of learning difficulties and in the manner to screen them. The results of this research have helped to highlight the presence of explanatory factors underlying all of the interpretative perspectives when professionals in education have taken a position on the nature of learning difficulties in mathematics.

Moreover, this research showed the importance of considering factors related to the perspective of the social sciences when discussing about the methods used for screening the students with mathematics difficulties. In addition, in relation to the comments made in order to explain how the screening activity is realized, a rupture in the theoretical frameworks on which some respondents rely was observed in the analysis of their discourse on the methods of screening. By referring to the three interpretative perspectives of learning difficulties, it would be interesting to document the consistency of the discourse of professionals not only concerning the interpretation and the screening of these difficulties, but also according to the modalities relating to the attribution of a diagnosis as well as the implementation of a sequence of educational interventions.

\section{References}

[1] Ahmad, F. (2014). Étude des déterminants anthropodidactiques de l'usage des jeux à l'école maternelle dans l'enseignement des mathématiques (Unpublished doctoral dissertation). University of Bordeaux, France.

[2] Chopin, M. P. \& Sarrazy, B. (2014). Contribution anthropodidactique à l'étude des effets de l'individualisme sur la création des inégalités scolaires. Éducation \& Didactique, 8 (2), 9-24. 
[3] Giroux, J. (2013). Étude des rapports enseignement/apprentissage des mathématiques dans le contexte de l'adaptation scolaire: problématique et repères didactiques. Éducation et Didactique, 7 (1), 59-86.

[4] Roine, C. (2009). Cécité didactique et discours noosphériens dans les pratiques d'enseignement en S. E. G. P. A: une contribution à la question des inégalités (Unpublished doctoral dissertation). Victor Segalen Bordeaux 2 University, Bordeaux, France.

[5] Chopin, M. P. (2007). Le temps didactique dans l'enseignement des mathématiques. Approches des modes de régulation des hétérogénéités didactiques [Unpublished doctoral dissertation, Victor Segalen Bordeaux 2 University]. TEL. https://tel.archives-ouvertes.fr/tel- 00542524

[6] Chopin, M. P. (2011). Le temps de l'enseignement. L'avancée du savoir et la gestion des hétérogénéités dans la classe. Rennes University Press.

[7] Lemoyne, G. et Lessard, G. (2003). Les rencontres singulières entre les élèves présentant des difficultés d'apprentissage en mathématiques et leurs enseignants. Éducation et francophonie, 21 (2), 13-44. https://doi.org/10.7202/1025772ar

[8] Najar, R. (2010). Effets des choix institutionnels d'enseignement sur les possibilités d'apprentissage des étudiants [Unpublished doctoral dissertation, Paris Diderot University (Paris 7)]. http://pf-mh.uvt.rnu.tn/43/1/These.pdf

[9] Roiné, C. (2012). Analyse anthropo-didactique de l'aide mathématique aux " élèves en difficulté »: l'effet Pharmakéia. Carrefours de l'éducation, 1, 131-147. https://doi.org/10.3917/cdle.033.0131

[10] Sarrazy, B. (2006). Fondements épistémologiques et ancrages théoriques d'une approche anthropo-didactique des phénomènes d'enseignement des mathématiques. In A.-C. Mathé et É. Mounier (dir.), Actes du séminaire national de didactique des mathématiques (p. 79-99). IREM of Paris.

[11] Charland, J.- P. (2005). Histoire de l'éducation au Québec: de l'ombre du clocher à l'économie du savoir. Editions du renouveau pedagogique Inc.

[12] Government of Quebec. (1997). Réaffirmer l'école. Prendre le virage du succès. Rapport du groupe de travail sur la réforme du curriculum. Government of Quebec.

[13] Government of Quebec. (1999). Une école adaptée à tous ses élèves: Politique de l'adaptation scolaire. Government of Quebec.

[14] Proulx, J. P. et Charland, J. P. (2009). Le système éducatif du Québec: De la maternelle à l'université. Cheneliere Education.

[15] Gauthier, C. et Saint-Jacques, D. (2002). La réforme des programmes scolaires au Québec. Laval University Press.

[16] Government of Quebec.. (2015). Bulletin statistique de l'éducation, 43. Government of Quebec.

[17] Homsy, M. et Savard, S. (2018). Décrochage scolaire au Québec: dix ans de surplace, malgré les efforts de financement. Quebec Insitute.

[18] Legault, F. (2013). Analyse du modèle d'intégration des élèves handicapés ou en difficulté d'adaptation ou d'apprentissage. Teaching syndicate of Haut-Richelieu.

[19] Government of Quebec. (2000). Élèves handicapés ou élèves en difficulté d'adaptation ou d'apprentissage (EHDAA): définitions. Government of Quebec.

[20] Government of Quebec. (2007). L'évaluation des apprentissages au secondaire. Cadre de référence. Government of Quebec.

[21] Rajotte, T. (2014). La résolution de problèmes de proportionnalité chez les élèves de sixième année du primaire avec ou sans TDA/H identifié [Unpublished doctoral dissertation, University of Quebec at Rimouski]. Archipel. https://archipel.uqam.ca/7152/

[22] Martin, V. et Mary, C. (2010). Particularités de l'enseignement des mathématiques à des élèves en classes régulières ou spéciales. In V. Freiman, A. Roy et L. Theis (dir.), L'enseignement de mathématiques dans et à travers des contextes particuliers: quel support didactique privilégier? Proceeding of the annual congress of the Groupe des didacticiens des mathématiques of Quebec (p. 229-240). Moncton University.

[23] Rajotte, T., Giroux, J. et Voyer, D. (2014). Les difficultés des élèves du primaire en mathématiques, quelle perspective d'interprétation privilégier? McGill Journal of Education, 49 (1), 67-87. https://doi.org/10.7202/1025772ar

[24] Giroux, J. (2010). Pour une différenciation de la dyscalculie et des difficultés d'apprentissage en mathématiques. Dans V. Freiman, A. Roy et L. Theis (dir.), L'enseignement de mathématiques dans et à travers des contextes particuliers: quel support didactique privilégier? Proceeding of the annual congress of the Groupe des didacticiens des mathématiques of Quebec (p. 148-158). Moncton University.

[25] Roine, C. (2015). La fabrication de l'élève en difficulté. Éducation et $\quad 37$. https://doi.org/10.4000/edso.1138

[26] Ayala, J. et Roditi, E. (2014). Inégalités sociales et apprentissages en mathématiques: les énoncés et les exercices seraient-ils eux-mêmes des différenciateurs? Recherches en didactiques, 17, 45-64. https://doi.org/10.3917/rdid.017.0045

[27] Sarrazy, B. (2001). Les interactions maître-élèves dans l'enseignement des mathématiques. Contribution à une approche anthropo-didactique des phénomènes d'enseignement. Revue française de pédagogie, 136, 117-132. https://doi.org/10.3406/rfp.2001.2832

[28] Mamas Mavoungou, E. L. (2016). Les rapports personnels des enseignants $d u$ primaire aux objets «variation» et "covariation» comme conséquence des choix institutionnels pour leur formation initiale [Unpublished master dissertation, Montreal University]. Papyrus. http://hdl.handle.net/1866/19014

[29] Brousseau, G. (1998). Théorie des situations didactiques. La Pensee sauvage editions.

[30] Sarrazy, B. (2002). Pratiques d'éducation familiale et sensibilité au contrat didactique dans l'enseignement des mathématiques chez des élèves de 9-10 ans. La revue internationale de l'éducation familiale, 6 (1), 103-130.

[31] Crahay, M, Wanlin, P., Issaeiva, E et Laduron, I. (2010). Fonctions, structuration et évolution des croyances (et connaissances) des enseignants. Revue française de pédagogie, 172, 85-129. https://doi.org/10.4000/rfp.2296 
[32] Lessard, G. (2014). L'accroissement de la pertinence institutionnelle de dispositifs didactiques d'enseignement des mathématiques afin de s'extirper des mécanismes de réduction des exigences auprès des «élèves en difficulté». In C. Mary, $\mathrm{H}$. Squalli, L. Theis et L. DeBlois (dir.), Recherches sur les difficultés d'enseignement et d'apprentissage des mathématiques: regard didactique (p. 113-131). University of Quebec Press.

[33] Rajotte, T., Germain, M.-P., Beaupre, S. et Beaudoin, D. (2018) The Influence of Social Factors on Learning Difficulties in Mathematics: Testing the Anthropo- Didactic Approach. International Journal of Elementary Education. 7 (1), 13-22. https://doi.org/10.11648/j.ijeedu.20180701.13

[34] Van Haecht, A. (2006). L'école à l'épreuve de la sociologie: La sociologie de l'éducation et ses évolutions. De Boeck University Editions.

[35] Giroux, J. (2015, 1er octobre). Difficultés des élèves en mathématiques: apports de la didactique [conférence]. Pedagogical High School of Canton de Vaud. Teaching and Research Unity: Mathematical Didactics and Natural Science.

[36] Godin, J. (2017). L'analyse réflexive en enseignement: les enseignants du secondaire de l'école d'Iberville [Unpublished master dissertation, University of Québec in AbitibiTeemiscamingue].

https://depositum.uqat.ca/id/eprint/736/

Depositum.

[37] Fortin, M. F. (2010). Fondements et étapes du processus de recherche: Méthodes quantitatives et qualitatives (2e éd.). Cheneliere Education.

[38] Beaud, S. et Weber, F. (2010). Le guide de l'enquête de terrain. La Decouverte editions.

[39] Hess, U., Senécal, S. et Vallerand, R. J. (2000). Les méthodes quantitative et qualitative de recherche en psychologie. In R. J. Vallerand et U. Hess. (dir.), Méthodes de recherche en psychologie (p. 507-529). Gaetan Morin Editeur.

[40] L'Ecuyer, R. (1990). Méthodologie de l'analyse développementale de contenu. University of Quebec Press.
[41] Deslauriers, J.-P. (1997). L'induction analytique. In J. Poupart, J.-P. Deslauriers, L.-H. Groulx, A. Laperrière, R. Mayer et A. P. Pires (dir.), La recherche qualitative: Enjeux épistémologiques et méthodologies (p. 293-332). Gaetan Morin Editeur.

[42] Miles, M. B. et Huberman, A. M. (2003). Analyse des données qualitatives. De Boeck.

[43] Lajoie, C. et Bednarz, N. (2014). La résolution de problème en mathématiques au Québec: évolution des rôles assignés par les programmes et les conseils donnés aux enseignants. Éducation $\begin{array}{lllll}\text { et } & \text { francophonie, } & 42 & \text { (2), } & \text { 7-23. }\end{array}$ https://doi.org/10.7202/1027903ar

[44] Peker, M. (2016). Mathematics teaching anxiety and self-efficacy beliefs toward mathematics teaching: A path analysis. Education Research and Reviews, 11 (3), 97-104. http://doi.org/10.5897/ERR2015.2552

[45] Mazzocco, M. M. et Thompson, R. E. (2005). Kindergarten predictors of math learning disability. Learning Disabilities Research \& Practice, $20 \quad$ (3), 142-155. https://doi.org/10.1111/j.1540-5826.2005.00129.x

[46] Barrouillet, P. (2006). Les troubles de l'arithmétique et la dyscalculie. In P. Barrouillet et V. Camos (dir.), La cognition mathématique chez l'enfant (p. 181-210). Solal.

[47] American Psychiatric Association. (2015). DSM-V: Diagnostic and Statistical Manual of Mental Disorders. Elsevier Masson.

[48] Bronfenbrenner, U. (2004). Making human being human. Bioecological perspectives on human development. Sage Publications.

[49] Fougeyrollas, P., Cloutier, R., Bergeron, H., Cote, J. et St-Michel, G. (1998). Classification québécoise: Processus de production $d u$ handicap. International Network on the Disability Creation Process.

[50] Cherel, C. (2005). Deux élèves en difficulté s'intègrent à une classe ordinaire le temps... des mathématiques. La Bande didactique editions. 